\title{
Diagnosis as a fundamental element for the safe exploitation of marine power plants
}

\author{
A. Charchalis \\ Mechanical Faculty, Gdynia Maritime University, Poland
}

\begin{abstract}
This paper presents possible ways of identifying the operating states of naval gas turbines by the Base Diagnostic System (BDS) application. The system configuration, testing means and methods are demonstrated in this paper, whilst the application of methods of vibroacoustic analysis in naval technology is also discussed. BDS is used in ships that are powered by the COGAG power plant. This paper examines the permissible in-service imbalance and appropriate assembly of turbine rotors on the basis of selected vibroacoustic parameters, as well as the determination of their permissible operation time resources. Another element of BDS that will be analysed in this paper is the vibration control of misaligned propulsion shafts.
\end{abstract}

Keywords: marine gas turbine, technical diagnostics, diagnostic system, testing means and methods, diagnostic software, risk analysis.

\section{Introduction}

As a result of developments brought on by technical advances, there is a great demand for highly specialized services that meet the requirements of the complex technology that is currently on board ships. In this paper we present the diagnostic systems that have been created to support the exploitation of the vessel power plant with gas turbines. Contemporary ships are complex constructions with enormous power levels reaching $100 \mathrm{MW}$. Due to navigational and environmental concerns, as well as safety and protection of human life and property, these ships require highly qualified crews in order to operate. As a consequence, the necessary educational standards for future ship captains as well as engine room officers, who are responsible for operating the ship's equipment, are constantly increased. The requirements set by maritime organizations (IMO) indicate the great importance of practical classes and 
laboratory training as well as training performed on simulators. It is for these reasons that during the learning process, with the exception of a certain number of classroom hours on the simulators, the trainees are required to participate in laboratories where real current on-board diagnostic methods are being applied, with specific regard to engine room operation. In this paper, an example of application of a basic diagnostic method in the didactic process of training related to ships' gas turbines has been examined. The main task of the diagnostic systems is to improve safety at sea. The use of such systems is extremely important when dealing with complicated devices, when technical staff is frequently changed and breakage can cause a considerable loss. Gas turbine engines can be classified as such devices.

In the case of gas turbines, the requirements related to marine operation are especially notorious. This is due to:

- a high volume intensity of the air flow through the engine, up to $80 \mathrm{~m}^{3} / \mathrm{s}$,

- a high level of the load of the engine,

- the complexity and sometimes impossibility of a thorough inspection of the engine,

- $\quad$ the requirement of the high level of purity of fuel, oil and air,

- exploitation by frequently changing crews,

- $\quad$ the fact that the gas turbines work mostly on partial load.

\section{Base Diagnosis System}

The application of periodical or on-line diagnostic procedures make it possible to operate ship propulsion systems in accordance with their current technical state [3]. Especially, taking into consideration that the ship's gas turbines' hourly period of scheduled maintenance is presently the criteria for determining maintenance time. This exploitation strategy makes the early scheduling of maintenance operations and their logistical assurance possible. However, at the same time, it contributes to increased costs because of the system of replacing elements (often still technically serviceable ones) makes it impossible to detect the early symptoms of failures, which may occur before the end of a maintenance period.

The use of naval gas turbines requires professional technical supervision, something that cannot be provided by the crews of small vessels such as those mainly used by the Polish Navy. Therefore, it was decided to support the crews of such vessels with the "Base Diagnostic System of Naval Gas Turbine Engines" (BDS). An organisation chart of BDS is shown in Figure 1. The system is applied for periodical inspections of engine condition and particularly in the case of:

- annual maintenance;

- $\quad$ the need to prolong the mean time between major repairs;

- identification of an abnormal running found during routine maintenance. 
The Base Diagnostic System consists of a series of diagnostic positions and facilitates a complex examination of engine conditions by EDP (Electronic Data Processing) application. The BDS (consequently) is capable of working out the prognosis for future engine operation. An operating decision is worked out on the basis of appropriately prepared measurements of the engine parameters. These are subsequently converted into diagnostic parameters according to the flow diagrams created for computer programs.

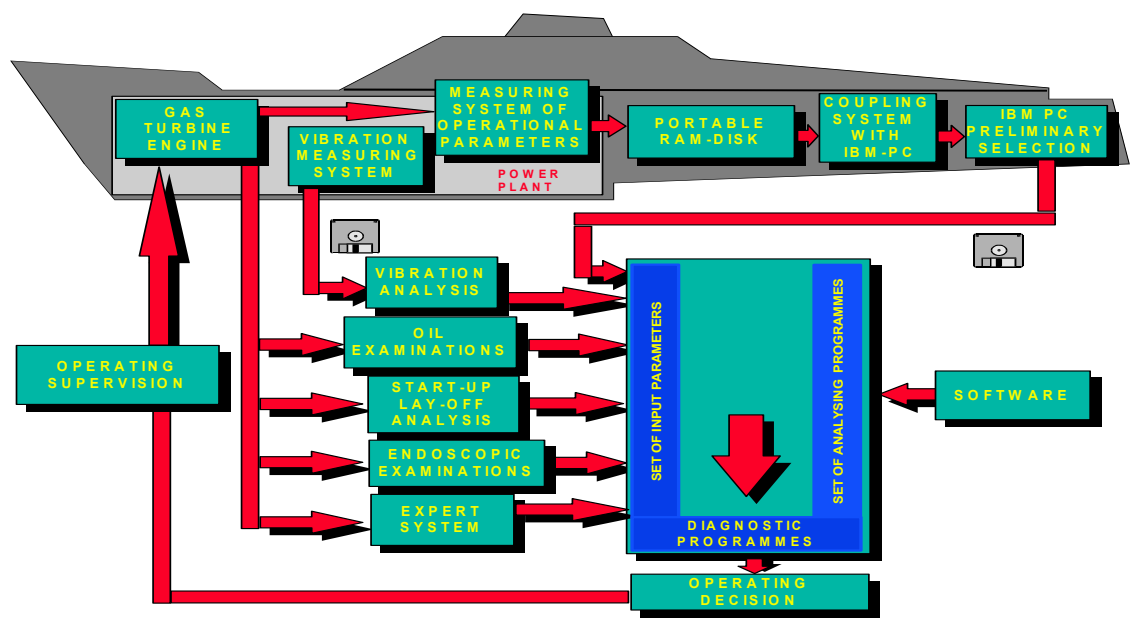

Figure 1: Base diagnostic system of naval gas turbine engines.

During BDS creation it was established that diagnostic information would be gathered:

- from the operating documentation of the vessel (an engine log-book),

- from an automatic measuring-registering device;

- through examination of special parameters describing the conditions of an engine e.g. measurement of vibrations and impurity of oil, endoscopic examination, registration of start-up and lay-off processes and so on;

- $\quad$ on the basis of interviews with experts and their opinions.

The BDS enables the accomplishment of the following tasks:

a. Detection of engine conditions that may lead to defects and even to a breakdown.

b. Creation of a diagnosis of the ship's supervising-measuring system.

c. Maintenance of a current evaluation of the engine characteristics fouling intensity of engine passages.

d. Restoration of the engine to the original state by washing the passages.

e. Maintenance of a database of each engine and vessel and making a prognosis from changes in the engine operating condition. 
From a technical point of view, the BDS is equipped with a special supervising-measuring device capable of carrying out numerous tasks on the grounds of measured values of various parameters of the engine.

The system configuration is based on operating experiences in aviation but the computer measuring system, diagnostic software, research methods and database are original.

In order to work out all tasks securing correct gas turbine operation, the BDS is equipped with the following special apparatus:

- for measuring and analysing vibration parameters;

- oil-position examination on metal particle contents and other impurities;

- $\quad$ computer measuring system of start-up and lay-off parameters;

- computer measuring system of operational parameters;

- programmable analyser of high-changeable signals;

- endoscopes;

- $\quad$ automatic test equipment for safety devices and supervising-measuring apparatus of the engines;

- computer database.

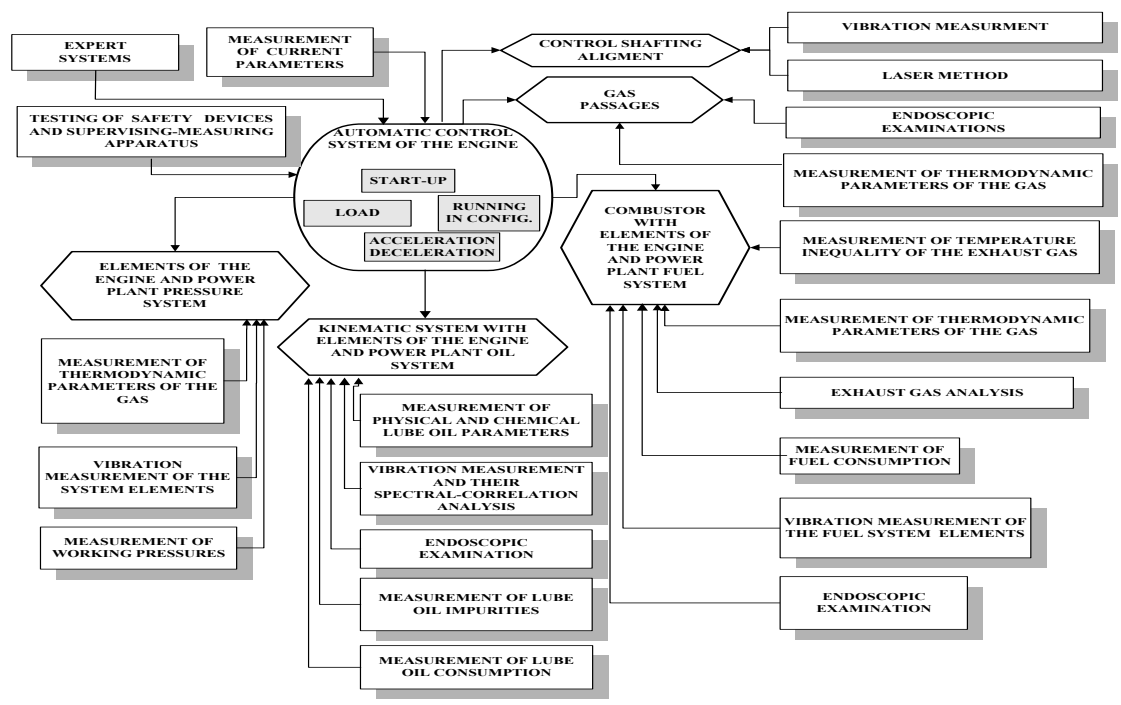

Figure 2: $\quad$ Methods and means of gathering diagnostic parameters.

The methods for gathering diagnostic parameters for the condition evaluation of different sub-assemblies of the engine are presented in Figure 2.

The engine is divided into five modules:

- automatic control system;

- gas passages;

- combustor with elements of the fuel system; 
- $\quad$ kinematic system with elements of oil system;

- element pressure system.

An operating condition of each module can be ascertained by the application of special diagnostic tools giving as a result a set of diagnostic parameters.

The measurement and analysis of the vibration is one of the most important parts of the diagnostic system. This diagnostic system is multi-symptomatic, so an evaluation of the technical state of each element can be obtained based on different methods. For example, the examination of a kinematics system with elements of the engine oil system is made by:

- measurement of physical and chemical lub oil parameters;

- vibration measurement and their spectral-correlation analysis;

- endoscopic examination;

- measurement of lube oil impurities by the radio isotopic method;

- measurement of lube oil consumption.

\section{Object of the investigation}

To obtain reliable data on diagnostic parameters, an examination of the gas turbines installed in the present propulsion system was carried out by means of the multi-symptom diagnostic model. One of the main features of this model consists of recording and analysing vibroacoustic signals. The investigation was aimed at determining permissible in-service imbalance and the appropriate assembly of turbine rotors on the basis of selected vibroacoustic parameters, and - finally - determining their permissible operation time resources. The analysis was based on the following assumption: if the degradation of the technical state of the gas turbine rotor sets is a function of their operation time (at a load spectrum assumed to be constant), then it is possible to select from the recorded vibration signal spectrum such parameters whose changes can be unambiguously assigned to the operation time [1,2]. A second important problem is shaft misalignment between engines and reduction boxes and between propeller and reduction box. Dynamic reactions, resulting from exceeding the allowable alignment deviations of the torque transmission elements can cause failure of the propulsion system and even lead to a loss of mobility of the vessel for a relatively short period of time [2]. Therefore, diagnostic control of the gas turbine power plant in operation becomes necessary.

\section{Diagnosis of rotor imbalance}

The dynamic problems of marine gas turbine engines (MGTE) are connected with such basic elements as: rotors, bearings, struts of bearings, engine bodies, types of substructure, hydro- and meteorological conditions during sea trials and gas flow parameters inside the engine. The quality of work process and stability of MGTE are also related to the state of these parameters. The dissipation of energy in rotating machines is displayed as torque, revolutions, temperature, gas flow and vibration. Vibrations are related to:

- an imbalance of rotors; 
- $\quad$ an increase in the tolerated axis slope of MGTE shafts, misalignment;

- $\quad$ the blade tips with the inner roller;

- the wear of axis and radial bearings;

- $\quad$ the asymmetry of springiness and damping characteristics of rotor and their parts;

- $\quad$ an irregularity of gas flow forces.

Emission of vibration provides a lot of information, including determination of the technical state of the devices. Measurements of vibration, their identification, classification, and mathematical analysis, including trends, provide information on the current technical state and it enables prediction of wear processes in the future. Vibration analysis of MGTE during sea trials is accomplished by two different procedures:

- online, in real time;

- offline, periodic or single measurements.

Both procedures have advantages and disadvantages. The online system enables permanent control of vibration parameters in real time. It allows us to monitor vibration parameters, holding memory and shutting down the engine in a critical state. The data preview of memory can activate the trend functions and it shows changes of frequency or time parameters of vibration as a function of operational time. The disadvantages of this system are linked with costs because software and hardware are stationary and sometimes individual. The objects of this research did not possess online monitoring systems and there were only four propulsion plants. For this reason, a periodical offline diagnostic system was applied.

For performing the investigations, the following measuring instruments were used: FFT-2148 analyser and PULSE v 9.0 software by Bruel \& Kjaer. These instruments made it possible to collect and process the measured data. Measuring transducers (accelerometers) were fixed to steel cantilevers located on the flange of the low-pressure (LP) compressor only. The decision to carry out the investigations with the use of the transducer fixed to the LP compressor flange resulted from a lack of transducers and equipment suitable for measuring signals at temperatures as high as $200^{\circ} \div 300^{\circ} \mathrm{C}$ occurring on the high-pressure (HP) compressor flange.

The fixing accelerometers' cantilevers are characterised by a natural resonance of vibration, whose frequency value differs from harmonic frequencies, due to the rotation speed of the turbine rotors and their harmonics. The measurements were taken perpendicularly to the rotation axis of the rotors over the main bearings. This choice was made on the basis of theoretical consideration of excitations due to imbalanced shaft rotation, and results of preliminary investigations of the object [5]. As signals usable for the "defectsymptom" relation, the turbines' producer selected the following magnitudes:

- $\quad Y_{\text {LPC }}$ - harmonic RMS value of vibration velocity amplitude connected to the LP rotor of compressor;

- $\quad \mathrm{Y}_{\mathrm{HPC}}$ - the same, but connected to an HP rotor of compressor;

- $\quad \mathrm{Y}_{\mathrm{RMS}}-\mathrm{RMS}$ value of the vibration velocity amplitude within the range of $35 \mathrm{~Hz} \div 400 \mathrm{~Hz}$. 
The choice was supported by the time-between-repair values scheduled by the turbines' producer. For the purposes of this investigation a simplification was made, which consisted of assuming that the values of the post-repair turbine vibration symptoms are equal to those of a new turbine. It was necessary to make this assumption because of a rather low number of investigated objects (only eight turbines of each type). The turbines' producer specified the following limit values of RMS vibration velocity amplitude (see Table 1).

Table 1: Acceptable ranges of vibration.

\begin{tabular}{|c|c|c|}
\hline & $\begin{array}{c}\text { permissible value } \\
\text { of Yrms }\end{array}$ & $\begin{array}{c}\text { permissible value of } \\
\text { harmonics Y }\end{array}$ \\
\hline $\begin{array}{c}\text { DR 76 } \\
\text { engines }\end{array}$ & $24[\mathrm{~mm} / \mathrm{s}]$ & $17[\mathrm{~mm} / \mathrm{s}]$ \\
\hline
\end{tabular}

In order to obtain uniform diagnostic procedures regarding imbalance assessment of turbine rotors, the dimensionless parameters characterising those states were applied. On the basis of theoretical considerations as well as pursuant to the results of other diagnostic investigations carried out for some years, the following parameters were selected as the most sensitive:

S1 - the ratio of the mean vibration velocity amplitude of a given rotor $\left(1^{\text {st }}\right.$ harmonic) and the velocity component relevant to $2^{\text {nd }}$ harmonic excitation frequency of the rotor in question

S2 - the ratio of the mean vibration velocity amplitude of a given rotor $\left(1^{\text {st }}\right.$ harmonic) and the velocity component relevant to $3^{\text {rd }}$ harmonic excitation frequency of the rotor in question.

During operation, the limited values of dimensionless parameters of low and high-pressure rotors were assessed (see Table 2).

Table 2: $\quad$ Limit ranges of the vibration pointer.

\begin{tabular}{|l|l|l|l|l|}
\hline & $\mathrm{S} 1_{\mathrm{SNC}}$ & $\mathrm{S} 2_{\mathrm{SNC}}$ & $\mathrm{S} 1_{\mathrm{SWC}}$ & $\mathrm{S} 2_{\mathrm{SWC}}$ \\
\hline $\begin{array}{l}\mathrm{DR} \\
\text { engines }\end{array}$ & $\begin{array}{l}\min \\
1,0\end{array}$ & $\min 1,5$ & $\min 1,0$ & $\min 1,5$ \\
\hline
\end{tabular}

where: SNC - low pressure compressor rotor, SWC - high pressure compressor rotor.

One of the most important elements of the offline system is the database. Idle load and full power (nominal load) were taken for further consideration. Each spectrum was transferred as matrixes $\mathrm{M}_{\mathrm{S}}$ and copied like fingerprints to the database. Spectra were not synchronized to the revolutions of rotors, at the same loads, at various air temperature conditions and this caused the elaboration of the following procedure of identification: Measured spectra had $2 \mathrm{kHz}$ probe frequency and 800 lines, so sensitivity was $\pm 150 \mathrm{rpm}$. During tests, changes in the revolutions of the rotors varied $\pm 230 \mathrm{rpm}$, so it was decided to make pattern spectra using 400 lines for both loads. This appeared as an important point of analysis as a result of the sensitivity of typical spectra (see Figure 3). 


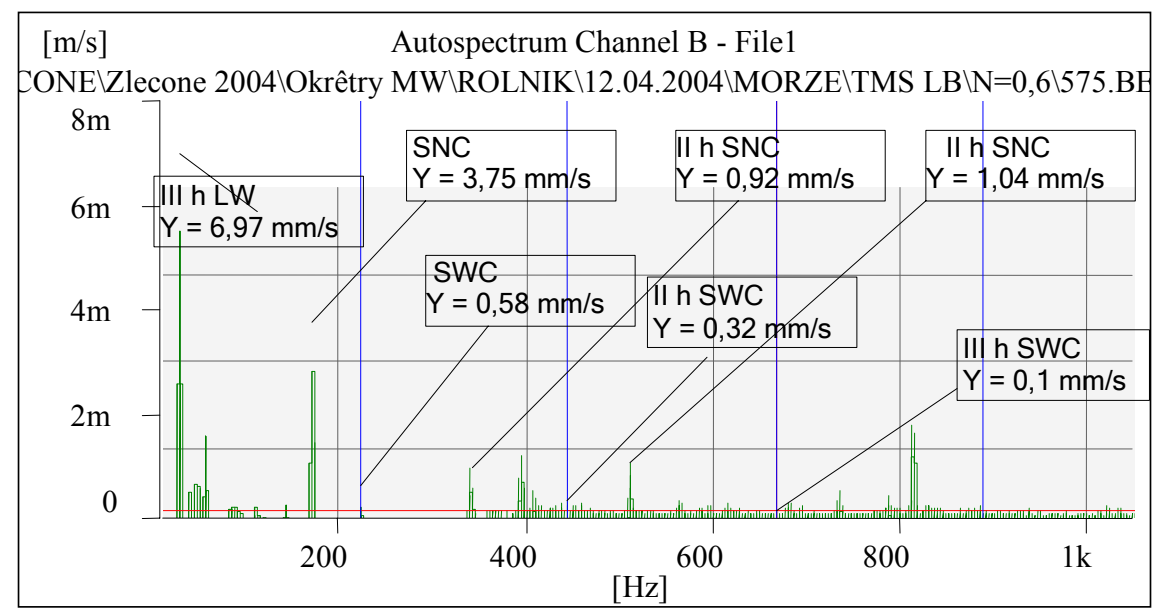

Figure 3: Typical pattern spectra in DR 77 engines, where: $\mathrm{SNC}=$ lowpressure compressor rotor and $\mathrm{SWC}=$ high-pressure compressor rotor and $\mathrm{h}=$ harmonics.

\section{Diagnosis of shaft misalignment}

The usual methods of measuring the coaxial parameters of the propulsion system require disassembling protection covers of shafting between the engines and the reduction gears. Measurement conditions make it necessary to suspend operation of the COGAG system for approximately $8-10$ days and obviously, this is an intrusive method. The vibroacoustic method presented in this paper allows us to assess permissible values of alignment parameters without stopping exploitation of the vessel. Moreover, the presented results are intended to form the database for elaboration of an online monitoring system of coaxial of torque transmission elements, applicable to the COGAG propulsion system in question.

Appropriate assembly of elements of the main engines and the other torque transmission elements (including propellers) is practically determined by a set of tolerated dimension and geometrical location requirements. This is called a geometrical dimension assembling chain [3]. Both typical and modular power plants are prone to coaxial deviation from its permissible values and in consequence, possible failures of one or more elements of the propulsion system. Excessive deviation can lead to the loads on bearings and gear teeth being much higher than calculated and result to their premature failure [4]. Application of vibroacoustic diagnostics to technical maintenance allows for a lower operational cost of the vessel by basing its operation on the current technical state and predicted failure states [1]. It was assumed that determining the relationship between the coaxiality parameters and changes of the recorded vibration signals should bring about identification of the proposed diagnostic model, consisting of: - A choice of geometrical parameters describing the position deviations, i.e. axis slope and displacement; 
- A choice of adequate parameters of the vibroacoustic signal;

- The determination of mutual relationships between sets of the coaxiality deviations and vibration diagnostic parameter values;

- Sensitivity assessment of the symptoms in question;

- Establishment of the database for statistical analysis and operational decision-making.

The research in question was only limited to control of the axis slope. This assumption was made to account for the influence of the displacement hull deflection on the element position of the serial multi-shaft system. In this case, the axis displacements are controlled solely during assembling the shafting system in the production and repair stages.

Examples of the investigation results are presented in the form of symptomchange regression functions at different displacement values of the vessel and different axis slope values. The results were approximated with the use of the least square method. The results were analysed by assigning the mean value of the vibration signal, i.e. the harmonic connected with the excitation frequency of vibration velocity amplitudes, to the measured axis slope value. Archive charts of the investigation results are exemplified in Figures 4 and 5. During the investigation no limit state of the axis slope of $Z=1 \mathrm{~mm} / \mathrm{m}$ was found in the propulsion system in question. A regression function of the symptom changes at different vessel displacement was calculated to determine the limiting (tolerated) values of the symptom. It was also stated, on the basis of analysis of the investigation results, that the mean signal value Ytn increases as the vessel's displacement increases, at the axis slope $\mathrm{Z}=$ constant.

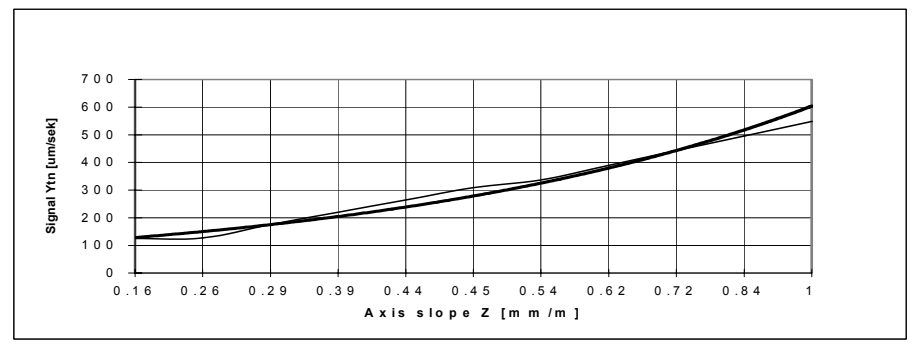

Figure 4: Symptom change regression functions at different slope values of the vessel's displacement of $\mathrm{D}=410 \mathrm{~m}^{3}$.

\section{Conclusions}

1. The proposed measurement method makes it possible to determine the limiting value of the Ytn symptom, which, if exceeded, indicates the inadmissible axis slope value and moreover, provides an unambiguous relationship between the axis slope and the vessel displacement values. 


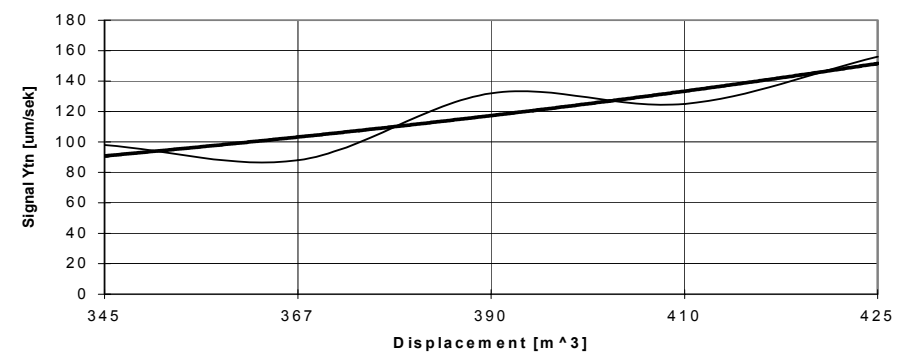

Figure 5: Symptom change regression functions at the different displacement values of the vessel and different axis slope values.

2. Implementation of the method to routine operation of the ship power plant could lead to an important reduction of the maintenance scope on the condition of extending the diagnostic control to all propulsion connections.

3. The proposed method could also be adapted to diagnosing other torque transmission components of similar propulsion system.

4. The online monitoring system may also be used for early detection of the symptoms of exceeding coaxiality allowances of selected components of the ship's gas turbine propulsion systems.

\section{References}

[1] Charchalis A.: Experimental Diagnostics of Naval Gas Turbines ISROMAC'98 Honolulu 1998.

[2] Charchalis A.: Multi Symptoms of Diagnosing of Marine Gas Turbines. 3 International Congress of Technical Diagnostics. Poznan 2004.

[3] Charchalis A., Grządziela A.: Diagnosing of naval gas turbine rotors with the use of vibroacoustic parameters. International Congress on Condition Monitoring and Diagnostic Engineering Management COMADEM 2001, Manchester, UK, pp 495 - 502.

[4] Charchalis A., Grządziela A.: Diagnosing of naval gas turbine rotors with the use of vibroacoustic parameters. The 2001 International Congress and Exhibition on Noise Control Engineering. The Hague, The Netherlands 2001, pp. 268.

[5] Downham E., Woods R.: The rationale of monitoring vibration on rotating machinery, ASME Vibration Conference, Paper 71- Vib-96, September 1971.

[6] Grządziela A.: Diagnosing the shafting alignment in the COGAG propulsion system by means of vibration measurement. The 2001 International Congress and Exhibition on Noise Control Engineering. The Hague, The Netherlands 2001, pp. 269.

[7] Grządziela A.: Diagnosing of gas turbine rotors with the use of vibroacoustic method, International Conference IMAM 2002, Rethymnon, Crete, Greece. 